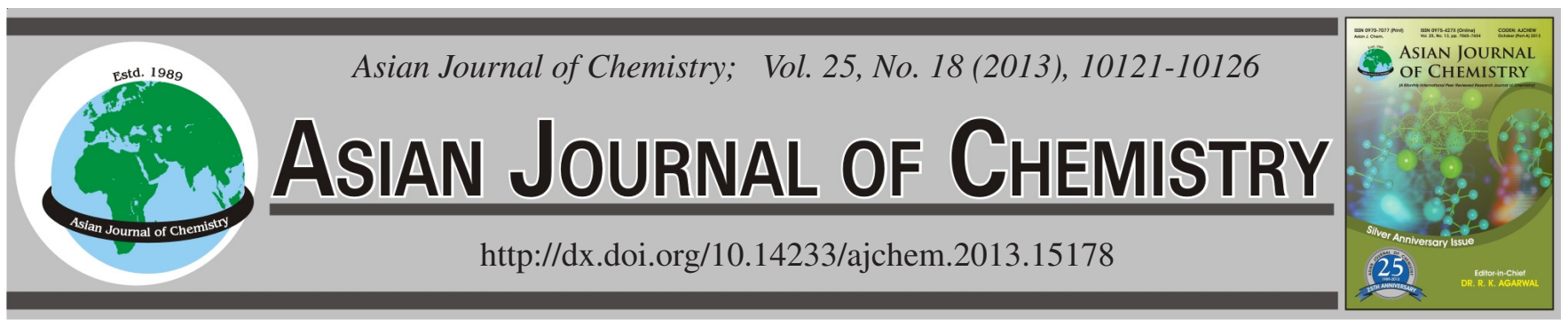

\title{
A Sensitive Electrochemical Sensor for the Detection of Formaldehyde Based on L-Alanine/Pt-Nanoparticles Modified Glassy Carbon Electrode
}

\author{
JiA-Hong HE ${ }^{1,2}$, Sheng-Tao Zhang ${ }^{1}$, Yan-Hua Cai ${ }^{2, *}$ and Zhong-Rong Song ${ }^{2, *}$
}

${ }^{1}$ Chemistry and Chemical Engineering College, Chongqing University, Chongqing 400030, P.R. China

${ }^{2}$ School of Materials and Chemical Engineering, Chongqing University of Arts and Sciences, Yongchuan 402160, P.R. China

*Corresponding author: E-mail: caiyh651@yahoo.com.cn (Yan-Hua Cai), szr1688@ 163.com (Zhong-Rong Song)

(Received: 19 January 2013;

Accepted: 8 November 2013)

AJC-14347

\begin{abstract}
A novel and sensitive electrochemical sensor for the detection of formaldehyde based on the platinum nanoparticles (Pt-NPs) and L-alanine modified glassy carbon electrode was developed by electrodeposition and self-assembly methods at room temperature. The structure and morphologies of the L-alanine/PtNPs sheets were characterized by SEM. The electrochemical behaviours of formaldehyde at the modified electrode in alkaline media was investigated through cyclic voltmmetry and chronoamperometry and the influence of scanning speed and the type and acidity of electrolytes, etc. conditions on the catalytic oxidation of formaldehyde was discussed. Results showed that the modified sensor had a strong electro-catalytic activity for the oxidation of formaldehyde. The oxidation peak current of formaldehyde was linear to concentrations in the range of 0.3 to $1050 \mu \mathrm{mol} / \mathrm{L}$, with the low detection limit of $0.14 \mu \mathrm{M}(\mathrm{S} / \mathrm{N}=3)$ and the recovery got by standard addition method was in the range of 95.6 to $103.2 \%$. The synergy effect of Pt nanoparticles and L-alanine contributed to the excellent electrochemical response towards the formaldehyde oxidation. The modified sensor we prepared exhibited higher sensitivity, broader linear range, lower detection limit, more excellent stability as well as good selectivity for the determination of formaldehyde.
\end{abstract}

Key Words: Platinum nanoparticles, L-alanine, Formaldehyde, Amperometry.

\section{INTRODUCTION}

The formaldehyde is an extremely important industrial raw material due to its chemical activity, high purity and relatively low-cost. It has been widely applied in the manufacture of building materials and numerous household products ${ }^{1-3}$. It is also an intermediate in consumer product such as detergents and soaps. Furthermore, it is used in pharmacology and medicine because of its sterilization property. It is a natural metabolite of living organisms. It can be found in fruits, vegetables, flesh and biological fluids of human origin.

Formaldehyde has a great impact on human health, because of its potential carcinogenic, mutagenic properties and its capability of forming intermediate and stable species of toxic and phytotoxic radicals. It can also cause irritation to eyes and nose, central nervous system damage, immune system disorders, blindness and respiratory disease ${ }^{4}$. Then the International Agency for Research on cancer classified formaldehyde as a human carcinogen ${ }^{5}$ and the US Environmental Protection Agency classified formaldehyde as a probable human carcinogen $^{6}$. Due to formaldehyde toxicity, the Word Health Organization furthermore established limits of exposure to formaldehyde at a maximum of $0.08 \mathrm{ppm}$ average over $0.5 \mathrm{~h}^{7}$. The
Occupational Safety and Health Administration (OSHA) also set a permissible exposure limit for formaldehyde of $0.75 \mathrm{ppm}$ for an 8-h work day ${ }^{8}$. The formaldehyde levels must be accurately monitored to comply with these standards. Therefore, simple and sensitive methods for determination of formaldehyde are needed for environmental control.

Various analytical methods have been reported for detecting formaldehyde in vapours or especially in liquid phase in recent years. The main common methods include spectrophotometry ${ }^{9}$, gas chromatography ${ }^{10}$, high-performance liquid chromatography $^{11}$, capillary electrophoresis ${ }^{12}$, fluorimetry ${ }^{13}$, etc. Although these methods have some advantages for the determination of formaldehyde, most of them require timeconsuming procedures, derivatization steps, or expensive instruments. So, it is necessary to develop a simple, sensitive and convenient method for the detection of formaldehyde. Compared with spectral and chromatographic analysis, electroanalytical method has been considered as a good alternative for formaldehyde detection due to its high sensitivity, selectivity and its potential for providing real-time measurements. Such modified electrodes enable to increase the selectivity of electroanalytic processes, which could not be achieved by using bare electrodes. 
In recent years, electrochemical sensors have been widely applied in the determination of formaldehyde concentration. Achmann et al. ${ }^{14}$ studied on the sensor electrode with multiwalled carbon nanotube films modified with graft percentage of amino-groups modified electrode to detect the concentration of formaldehyde. The result illustrated that the sensor displayed high chemical selectivity, fast response and good reproducibility to low concentration formaldehyde. Amperometric sensors in the potentiostatic mode using noble metals as electrode nanomaterials are also used for formaldehyde detection ${ }^{15}$. Metal nanomaterials have high effective surface areas and extraordinary electron-transport properties. Their using as electrochemical interface provides a rapid current response and high-detection sensitivity. Consequently, the electron transfer between the electrode and the probe molecules is accelerated. Zhang et al. ${ }^{16}$ introduced the electrodeposition of a nanostructured palladium in aluminum oxide membrane coated glassy carbon electrode (GCE). The proposed sensor not only possesses a broad linear range, good reproducibility and high sensitivity, but also exhibits a synergistic effect that minimizes poison formation. Yi et al. ${ }^{17}$ reported a novel formaldehyde detection method based on nanoporous palladiummodified $\mathrm{TiO}_{2}$ electrode in alkaline solutions. The sensor is low cost with high selectivity and long-term stability.

The purpose of this article was to develop a simple, selective and sensitive sensor method for determination of formaldehyde in aqueous solution, which was based on platinum nanoparticles and L-alanine modified on the glassy carbon electrode. The parameters affecting the performance of resultant sensors had also been investigated. The results demonstrated that the proposed method had additional advantages of being less time-consuming, high selectivity and sensitivity and simple instrumentation. Furthermore, the limit of detection of this method was better than other methods. These may promise this sensor a bright future for formaldehyde determination in environmental and industrial monitoring.

\section{EXPERIMENTAL}

Chloroplatinic acid $\left(\mathrm{H}_{2} \mathrm{PtCl}_{6}\right)$ was purchased from Sinopharm Chemical Reagent Co. Ltd. (Shanghai, China). L-alanine was obtained from Shanghai Kangda amino acid Company. Sodium hydroxide $(\mathrm{NaOH})$ and formaldehyde (HCHO, 37 wt. \%) were purchased from Chongqing Boyi Chemical Co. Ltd. They are used as received without further purification. Other chemicals were obtained from standard reagent suppliers. All reagents were analytical grade or above and all solutions were freshly prepared with doubly distilled water. All experiments are carried out at $25^{\circ} \mathrm{C}$.

Electrochemical measurements were carried out on a $\mathrm{CHI}$ 660B electrochemical workstation (Shanghai Chen Hua Instrument, china). The electrochemical cell contained a threeelectrode system composed of a bare or modified glassy carbon electrode as working electrode, a platinum wire as auxiliary electrode and a saturated calomel electrode as reference electrode. All potential were measured and reported versus the saturated calomel electrode. The test solutions were $20 \mathrm{~mL}$ $\mathrm{NaOH}$. All the electrochemical experiments were performed at an ambient temperature of $25 \pm 2{ }^{\circ} \mathrm{C}$. Scanning electron microscopy (SEM) measurements were carried out on a JSM6700F scanning electron microscope (Japan Electro Company).

Preparation of modified electrode: The sensor was fabricated by the following ways: firstly, prior to use, the glassy carbon electrode (GCE, $\phi=3 \mathrm{~mm}$ ) was polished repeatedly with $1.0,0.3$ and $0.05 \mu \mathrm{m}$ alumina powder, followed by successive sonication in acetone and doubly distilled water for $5 \mathrm{~min}$ and dried at room temperature. The glassy carbon electrode was immersed into $\mathrm{H}_{2} \mathrm{PtCl}_{6}$ solution containing $0.1 \mathrm{M}$ sulfuric acid (prepared in doubly distilled water and deaerated by bubbling with nitrogen). A constant potential of -0.2 $\mathrm{V}$ versus saturated calomel electrode was applied for $400 \mathrm{~s}$. Then the platinum nanoparticles were immobilized on the glassy carbon electrode via electrodeposition method. Secondly, the nano-platinum electrode was immersed into $0.05 \mathrm{~mol} \mathrm{dm}^{-3}$ $\mathrm{L}$-alanine solution for $2 \mathrm{~h}$ at room temperature to acquire a $\mathrm{L}$ alanine film on the surface of the modified electrode (denote as L-alanine/PtNPs/GCE/CME), then dried at room temperature. The electrode was characterized by cyclic voltammertry in $0.1 \mathrm{M} \mathrm{NaOH}$ and SEM. The fabricating steps are outlined in Scheme-I.

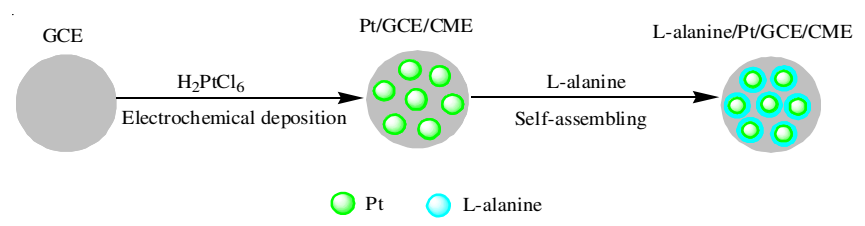

Scheme-I: Fabricating steps of the formaldehyde sensor

Electrochemical measurements: Electrochemical measurements were performed using CHI660 (Shanghai Chen Hua Instrument, China) with a conventional three-electrode system consisting of the prepared electrode as working electrode, a platinum plate as counter electrode and a saturated calomel electrode (SCE) as reference electrode. Firstly, before formaldehyde detection, L-alanine/PtNP/GCE electrode was activated by using successively cyclic sweeps between -0.6 and $0.5 \mathrm{~V}$ at $100 \mathrm{mV} \mathrm{s}^{-1}$ in $0.1 \mathrm{M} \mathrm{NaOH}$ solution, until a stable cyclic voltammogram profile was obtained. Before electrochemical treatment, all solutions used in the voltammetric system were deaerated with nitrogen for at least $10 \mathrm{~min}$ and during electrochemical measurement nitrogen atmosphere was maintained in electrochemical cell. The activated L-alanine/ PtNPs/GCE/CME electrode was evaluated as a formaldehyde sensor in $0.1 \mathrm{M} \mathrm{NaOH}$ solution at room temperature by cyclic voltammetry and chronoamperometry. Different concentrations of formaldehyde were prepared in $0.1 \mathrm{M} \mathrm{NaOH}$ solution before use. The potential mentioned in this paper was all relative to the potential of saturated calomel electrode.

\section{RESULTS AND DISCUSSION}

Characterization of $L$-alanine/PtNPs composite: SEM was employed to characterize the surface structure and morphology of the modified electrode. Fig. 1 showed the scanning electron micrography of the L-alanine/PtNPs compound film. The SEM image showed that the platinum nanoparticles were spheroidal with well-distributed size and the image also showed that the average size of nano-Pt was $40 \mathrm{~nm}$ approxi- 
mately. The results also indicated that L-alanine film was in favour of decentralization and adsorption of PtNPs and the synergy effect of platinum nanoparticles and L-alanine could accelerate the electron transfer between formaldehyde and electrode. In order to confirm the interface properties and compare electroactive surface of modified electrodes, more cyclic voltammetry experiments were carried out in different potentials.

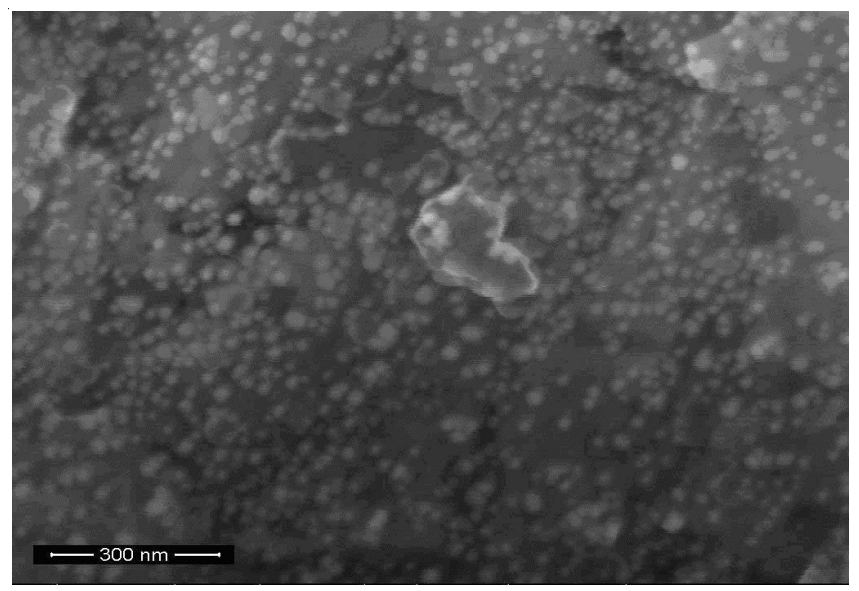

Fig. 1. SEM image of the surface of the modified electrode

Electrochemical behaviour of formaldehyde at $\mathrm{L}$ alanine/PtNPs/GCE/CME: The electrocatalytic activity of the L-alanine/PtNPs composite film modified glassy carbon electrode was demonstrated by the comparison of the cyclic voltammograms $(\mathrm{CVs})$ of $0.5 \mathrm{mM}$ formaldehyde in $0.1 \mathrm{M}$ $\mathrm{NaOH}$ records at three different working electrodes (Fig. 2). As shown in Fig. 2 (curve a), no response was observed from the bare glassy carbon electrode, it illustrated that the bare glassy carbon electrode electrode was no reaction in the alkaline solution. And there was an irreversible oxidation peak at $0.19 \mathrm{~V}$ on PtNPs/GCE/CME (curve b). Noticeably, curve c displayed that the oxidation current of formaldehyde on the L-alanine/PtNP/GCE/CME was increased compared with PtNPs/GCE/CME. Form the curve c, we could observed that the peak current at L-alanine/PtNPs/GCE/CME was nearly two times higher than the sum of response currents at PtNPs/GCE/ $\mathrm{CME}$ and bare glassy carbon electrode. Meanwhile, on the Lalanine/PtNPs/GCE/CME, the oxidation peak potential of formaldehyde shifted negatively to $-0.031 \mathrm{~V}$, the decrease in oxidation of over-potential and the enhancement of peak current indicated that the L-alanine/PtNPs/GCE/CME could efficiently promote the electro-oxidation of formaldehyde.

The improved performance of L-alanine/PtNPs composite may be explained by the following synergy hypothesis: the L-alanine has high specific surface area and the PtNPs has novel electronic transfer ability, the integration of $\mathrm{Pt}$ nanoparticles and L-alanine formed an electron-conducting network and ion-conducting matrix, the synergy effect of L-alanine and Pt NPs could lead to the larger electroactive area of the modified electrode for detecting the formaldehyde, which improved the electronic and ionic transport capacity of modified electrode, it also allowed for the electrooxidation through the L-alanine/PtNPs composite film and consequently facilitated the reaction between the formaldehyde and the

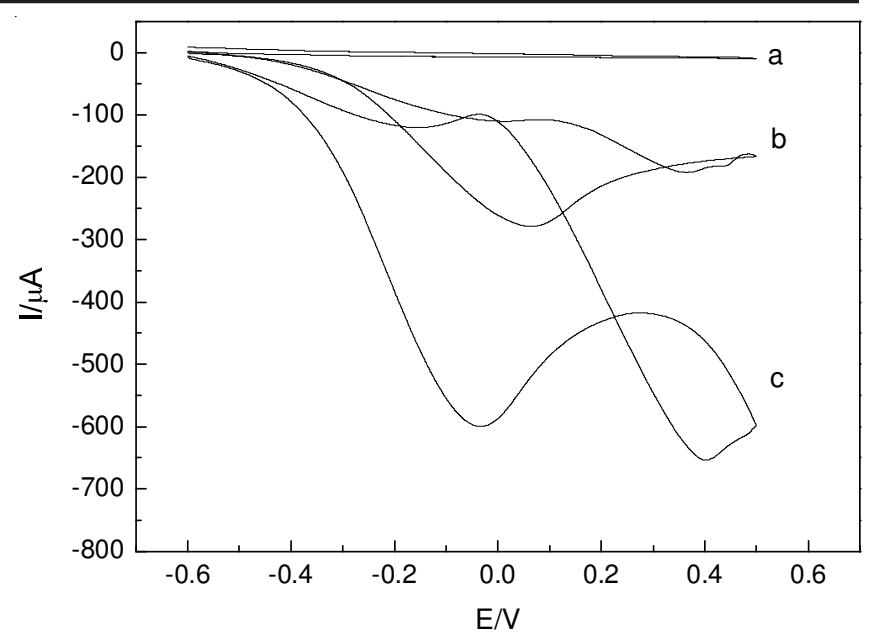

Fig. 2. Cyclic voltammograms of $0.5 \mathrm{mM}$ formaldehyde in $0.1 \mathrm{M} \mathrm{NaOH}$ at the bare glassy carbon electrode electrode (a), PtNPs/GCE/CME (b), $\mathrm{L}$-alanine/PtNPs/GCE/CME (c). The scan rate is $100 \mathrm{mV} \mathrm{s}^{-1}$

electrode surface, which in turn led to the increase in the amperometric response.

Effect of $\mathrm{NaOH}$ concentration on the cyclic voltammetric behaviour of the sensor: In most cases, $\mathrm{pH}$ of the solution is an important influence factor to the electrochemical reaction. Cyclic voltammogram was carried out to characterize the influence of solution $\mathrm{pH}$ on electrochemical behaviour of formaldehyde oxidation at the L-alanine/PtNPs/GCE/CME. In this work, some supporting electrolytes, such as phosphate buffer solution $\left(\mathrm{KH}_{2} \mathrm{PO}_{4}-\mathrm{Na}_{2} \mathrm{HPO}_{4}\right)$, acetate buffer solution $\left(\mathrm{CH}_{3} \mathrm{COOH}\right.$ $+\mathrm{CH}_{3} \mathrm{COONa}$ ), Britton-Robinson buffer solution (B-R), borate buffer solution and $\mathrm{NaOH}$ were investigated by cyclic voltammetry in order to optimize the response of formaldehyde at L-alanine/PtNPs/GCE/CME. The results showed that welldefined and sensitive peaks were observed when $\mathrm{NaOH}$ solution was used as electrolyte.

The effect of $\mathrm{NaOH}$ concentration on the current response of formaldehyde was also investigated by cyclic voltammogram measurement. The concentration of $\mathrm{NaOH}$ used was 0.05 , $0.08,0.1,0.12,0.15,0.2,0.25$ and $0.50 \mathrm{M}$, with the increase of the concentration, the peak current of formaldehyde increased. The peak current arrived at a maximum value when the concentration reached $0.1 \mathrm{M}$ and then decreased slightly. This phenomenon can be explained as that the ${ }^{\circ} \mathrm{OH}$ radical participated the electric oxidation reaction of formaldehyde and the low concentration of ${ }^{\circ} \mathrm{OH}$ radical can not satisfy the reaction's need, which can affect the reaction rate. While, excessive ${ }^{\circ} \mathrm{OH}$ radical may occupy the active center of the electrode surface, which make the reaction rate reduce. In this study, $0.1 \mathrm{M} \mathrm{NaOH}$ was chosen as the optimum electrolyte concentration.

Effect of varying scan rate on electro-oxidation of formaldehyde: Cyclic voltammograms of $1 \mathrm{mM}$ formaldehyde on L-alanine/PtNPs/GCE/CME with different scan rates in $\mathrm{NaOH}$ were shown in Fig. 3. It can be seen that with the increase of the scan rate, the oxidation peak currents increase gradually. Fig. 3B showed that the peak current increased linearly with the square root of scan rate in the range of 40$160 \mathrm{mV} \mathrm{s}^{-1}, \mathrm{i}_{\mathrm{pa}}=61.12-62.425 \mathrm{v}^{1 / 2}\left(\mu \mathrm{A}, \mathrm{mV} \mathrm{s}^{-1 / 2}, \mathrm{R}=0.9973\right)$. The results suggested that the kinetics of the overall process 

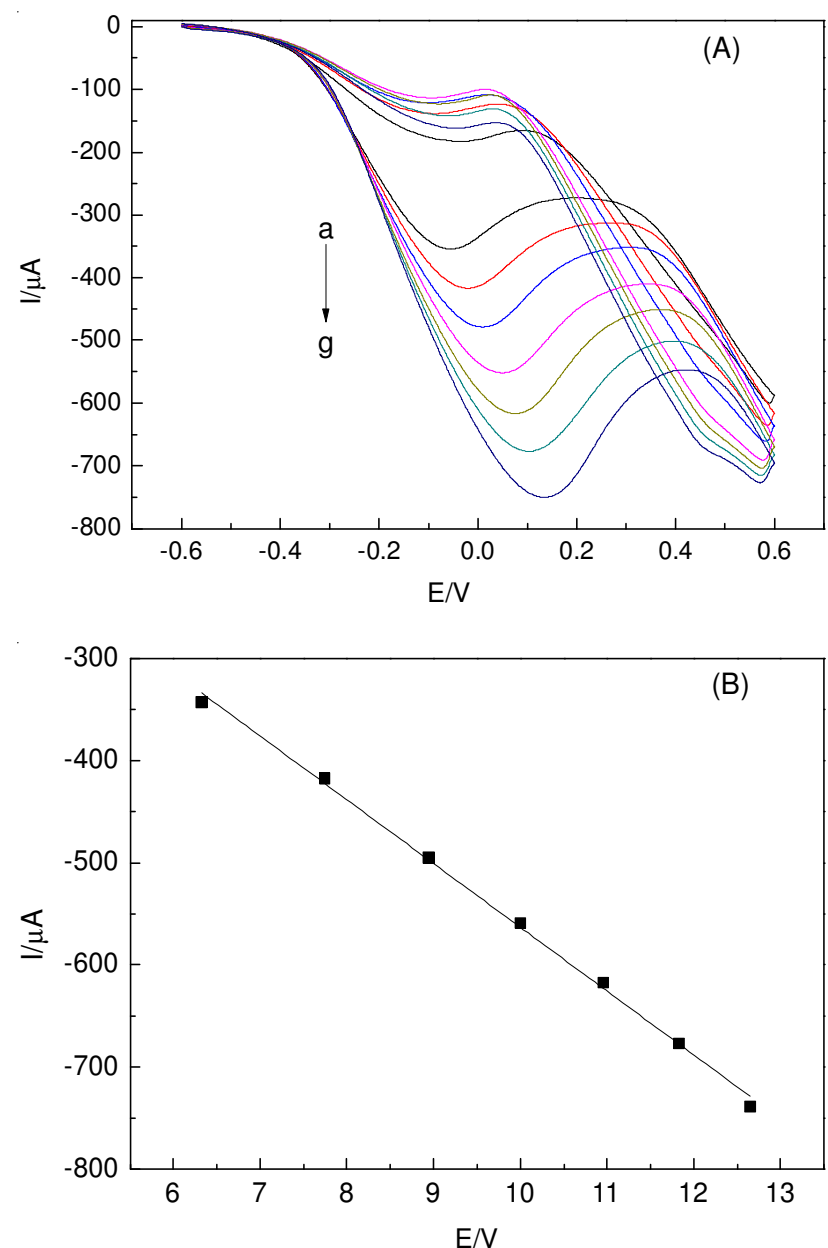

Fig. 3. Cyclic voltammograms of $0.5 \mathrm{mM}$ formaldehyde in $0.1 \mathrm{M} \mathrm{NaOH}$ on L-alanine/PtNPs/GCE/CME with different potential scan rates (from 1 to 6) 40, 60, 80, 100, 120, 140, $160 \mathrm{mV} \mathrm{s}^{-1}$

was controlled by a diffusion process in the range of scan rates. It was clear that the oxidation peak current increased with the rising of scan rate, while the peak potential shifted positively, indicating that the redox reversibility of formaldehyde was impaired with increasing sweep rate. It also demonstrated that the oxidation of formaldehyde became much harder and it was completely an irreversible process.

Amperometric detection of formaldehyde: The typical current-time plot of the sensor with successive injection of $5 \mu \mathrm{M}$ formaldehyde was given in Fig. 4 A. The working potential was set $-0.031 \mathrm{~V}$, where the amperometric response reached maximum value (Fig. 2). The sensor rapidly responded and reached a steady state within $5 \mathrm{~s}$ after the formaldehyde was added into solution, demonstrating that the sensor had a high sensitivity to formaldehyde. The fast response time and high sensitivity can also be ascribed to the well-defined surface area. Fig. 4B shows the calibration curve of the amperometric response. A good linear relationship was realized within the formaldehyde concentration range of $0.3 \mu \mathrm{M}$ to $1050 \mu \mathrm{M}$, with the detection limits of $0.14 \mu \mathrm{M}$ at a signal-to-noise ratio of 3 . The linear equations was expressed as $\mathrm{I}_{\mathrm{pa}}(\mu \mathrm{A})=0.6022-0.5375$ $\mathrm{C}_{\mathrm{FA}}(\mu \mathrm{M})$, with a correlation coefficient of 0.9993 .
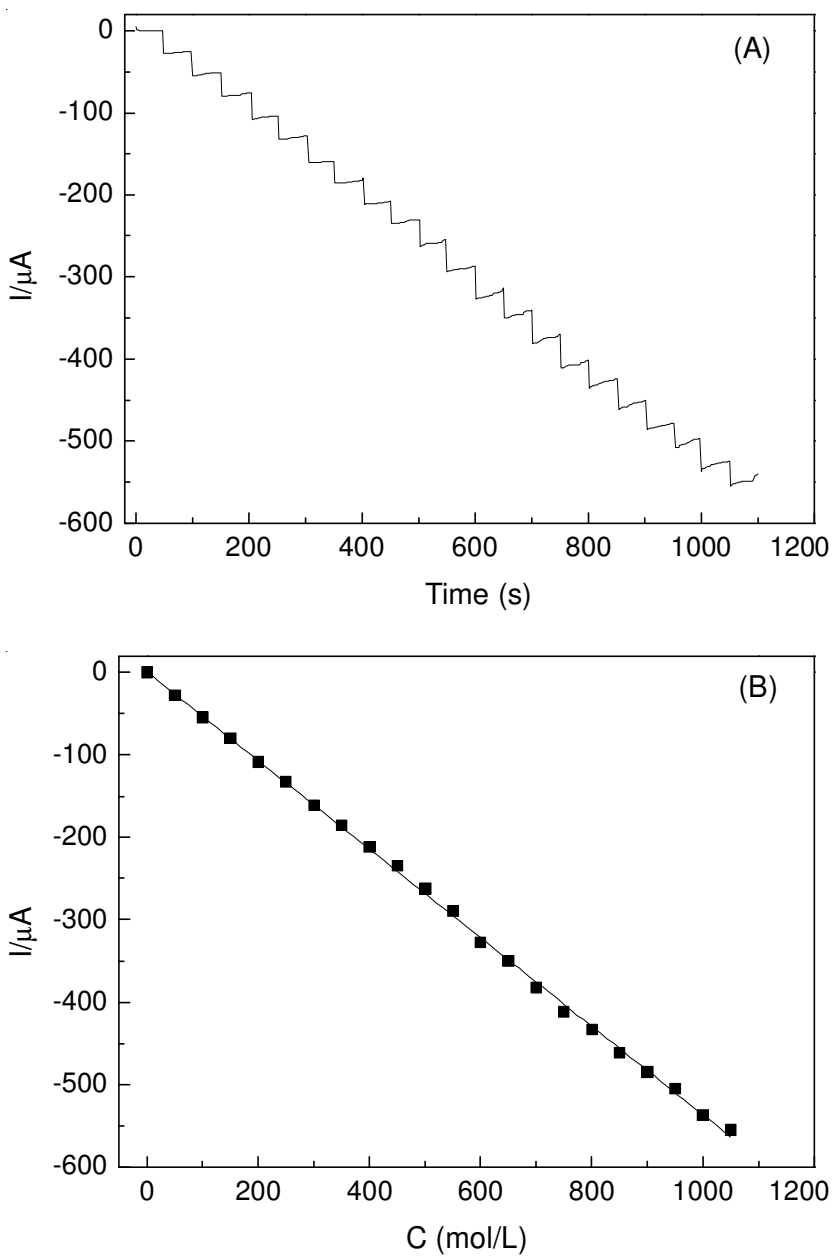

Fig. 4. (A) Current-time responses curve of the L-alanine/PtNPs/GCE/CME on increasing the formaldehyde concentration by $50 \mu \mathrm{M}$ in each step in $0.1 \mathrm{M} \mathrm{NaOH}$ at an applied potential of $-0.031 \mathrm{~V} v s$. saturated calomel electrode. (B) The calibration curve of formaldehyde

The comparison of the formaldehyde sensor as proposed in present study with other formaldehyde sensors, especially those sensors using electrochemical and enzymatic methods, for formaldehyde determination was given in Table-1. It can be seen that the L-alanine/PtNPs/GCE offered reasonable linear range for formaldehyde detection and the detection limit of formaldehyde was lower than some of previous repots. More importantly, it can be seen that the sensor developed in this

TABLE-1

COMPARISON OF DIFFERENT MODIFIED ELECTRODES

\begin{tabular}{|c|c|c|c|c|}
\hline Electrode fabrication & Detection potential $(\mathrm{V})$ & Linearity range $(\mu \mathrm{M})$ & Detection limit $(\mu \mathrm{M})$ & Ref. \\
\hline Nanoarry electrode-alcohol oxidase enzyme & 0.3 & $1-16,000$ & 0.5 & [18] \\
\hline Pd NW arrays electrode & 0.03 & $1-1,000$ & 0.5 & [19] \\
\hline Pt-Pd/Nafion/GCE & 0.58 & $10-1000$ & 3 & [20] \\
\hline $\mathrm{AgPd} / \mathrm{Ch}-\mathrm{IL} / \mathrm{GCE}$ & 0.05 & $60-20,000$ & 22 & [21] \\
\hline Palladium-doped screen-printed electrodes & 0 & $10-10,000$ & 2 & [22] \\
\hline L-alanine/PtNPs/GCE & -0.03 & $0.3-1050$ & 0.14 & This work \\
\hline
\end{tabular}


study works at a very low applied potential compared with other sensors $(-0.03 v s .0 .03,0.05,0.3,0.58)$, thus the possible interferences (e.g., methanol, ethanol, acetone etc.) should be considerably reduced.

Reproducibility and stability of the L-alanine/PtNPs/ GCE/CME: Both operational stability and long-time storage stability were considered as the most important factors of a sensor performance. Then, the reproducibility and stability of the sensor were evaluated. Under the same conditions, eight successive measurement of $0.5 \mathrm{mM}$ formaldehyde were operated with one L-alanine/PtNPs/GCE/CME at -0.031V. The relative standard deviation (R.S.D) of the sensor response to $0.5 \mathrm{mM}$ formaldehyde was $3.4 \%$ for eight successive measurements, showing that the proposed sensor possessed a good reproducibility. Three composite modified electrodes were made and their current responses to $0.5 \mathrm{mM}$ formaldehyde at $-0.031 \mathrm{~V}$ were investigated. The relative standard deviation (RSD) was $3.8 \%$, confirming that the fabrication detection method was highly reproducible.

The stability of the sensor was examined by measuring cyclic voltammograms of the modified electrode every two days. The current response of the sensor to formaldehyde remained $94 \%$ of its original response after 30 days. The sensor was used to measure the concentration of formaldehyde over 60 times in a solution of formaldehyde $(0.5 \mathrm{mM})$ in $\mathrm{NaOH}$ (0.1M). After the 60 cycles, the peak currents dropped by $2 \%$ for the L-alanine/PtNPs/GCE/CME. These results indicated that the L-alanine/PtNPs/GCE/CME demonstrated high stability in the electrochemical oxidation of formaldehyde.

Interference study and analytical application: The interferences of some ions and other organic compounds were also examined with $0.5 \mathrm{mM}$ formaldehyde. Measurement of oxidation current for six times and the average values were obtained (Table-2). If the presence of some ions and organic compound altered the oxidation peak current by less than $\pm 5 \%$, we considered that caused no interference. Some possible inorganic in the wastewater such as $\mathrm{Fe}^{3+}, \mathrm{Fe}^{2+}, \mathrm{K}^{+}$,
$\mathrm{Na}^{+}, \mathrm{Al}^{3+}, \mathrm{Cu}^{2+}, \mathrm{Mg}^{2+}, \mathrm{Co}^{2+}, \mathrm{NO}^{3-}, \mathrm{SO}_{4}{ }^{2-}, \mathrm{HPO}_{4}{ }^{2-}$ and $\mathrm{PO}_{4}{ }^{3-}$ were added in sodium hydrate solution containing $0.5 \mathrm{mM}$ formaldehyde, the results indicated that they had no influence on the oxidation peak current. Further, some organic compounds, which had the similar chemical structure with formaldehyde, such as methanol and formic acid, were investigated. The results indicated that 30 -folds sodium nitrite, 20 -folds acetone, 50 -fold methanol and formic acid had no influence on the peak current intensity. The good ability of anti-interference was largely attributed to the low working potential of -0.031 $\mathrm{V}$ used in the determination of formaldehyde.

In order to evaluate the performance and feasibility of this method for determination of formaldehyde, under the optimum conditions, actual water from Chongqing water supply company were determined by the proposed sensor. The original concentrations of formaldehyde in the water samples were tested to be $0 \mathrm{M}$ for all samples. Then, we added a certain concentration of formaldehyde into them, respectively, as simulative samples and determined them by a standard addition method. The results were shown in Table-3. The results were satisfactory, showing that the proposed sensor can be efficiently used for the determination of formaldehyde.

\section{Conclusion}

The electrochemical synthesis and characterization of L-alanine/PtNPs/GCE/CME electrode had been achieved. The proposed method was applied to the determination of formaldehyde in alkaline solution. Compared with bare glassy carbon electrode electrode, the L-alanine/PtNPs/GCE/CME electrode exhibited a higher catalytic activity for formaldehyde detection and the oxidative peak current was linear to the concentration of formaldehyde ranging from $0.3 \mu \mathrm{M}$ to $1050 \mu \mathrm{M}$ with a detection limit of $0.14 \mu \mathrm{M}$. The results showed that the fabricated formaldehyde sensor effectively detected formaldehyde in the presence of interferences such as sodium nitrite, acetone and methanol. Overall, the sensor has potential applications in practical analysis.

TABLE-2

THE INTERFERENCE FROM SOME IONS AND ORGANIC COMPOUNDS ON THE DETERMINATION OF FORMALDEHYDE

\begin{tabular}{cccccc}
\hline Interferences & Content $(\mathrm{mol} / \mathrm{L})$ & $\mathrm{RSD}(\%, \mathrm{n}=6)$ & Interferences & Content $(\mathrm{mol} / \mathrm{L})$ & $\mathrm{RSD}(\%, \mathrm{n}=6)$ \\
\hline $\mathrm{Fe}^{3+}$ & 0.015 & 2.2 & $\mathrm{~K}^{+}$ & 0.5000 & 1.9 \\
$\mathrm{Fe}^{2+}$ & 0.015 & 3.1 & $\mathrm{Na}^{+}$ & 0.5000 & 2.8 \\
$\mathrm{Al}^{3+}$ & 0.002 & 4.7 & $\mathrm{Cu}^{2+}$ & 0.0025 & 2.6 \\
$\mathrm{Mg}^{2+}$ & 0.005 & 1.8 & $\mathrm{Co}^{2+}$ & 0.0050 & 4.1 \\
$\mathrm{NO}_{3} \mathrm{CO}_{3}^{2-}$ & 0.500 & 3.6 & $\mathrm{SO}_{4}^{2-}$ & 0.5000 & 3.9 \\
$\mathrm{CO}_{4}^{2-}$ & 2.4 & $\mathrm{PO}_{4}{ }^{3-}$ & 0.5000 & 3.7 \\
\hline
\end{tabular}

TABLE-3

DETERMINATION RESULTS AND THE RECOVERY RATE OF WATER SAMPLES FROM CHONGQING WATER SUPPLY COMPANY $(n=6)$

\begin{tabular}{|c|c|c|c|c|c|}
\hline $\begin{array}{l}\text { Sample } \\
\text { number }\end{array}$ & $\begin{array}{l}\text { Original concentration of } \\
\text { formaldehyde }(\mu \mathrm{M})\end{array}$ & $\begin{array}{c}\text { Amount of standard } \\
\text { formaldehyde added }(\mu \mathrm{M})\end{array}$ & $\begin{array}{c}\text { Total amount of } \\
\text { formaldehyde found }(\mu \mathrm{M})\end{array}$ & $\begin{array}{c}\text { Recovery } \\
(\%)\end{array}$ & $\begin{array}{l}\text { RSD } \\
(\%) \\
\end{array}$ \\
\hline 1 & 0 & 10.00 & 9.87 & 98.7 & 3.0 \\
\hline 2 & 0 & 15.00 & 15.48 & 103.2 & 3.3 \\
\hline 3 & 0 & 20.00 & 19.28 & 96.4 & 3.1 \\
\hline 4 & 0 & 25.00 & 24.43 & 97.7 & 2.7 \\
\hline 5 & 0 & 30.00 & 30.42 & 101.4 & 2.4 \\
\hline 6 & 0 & 35.00 & 33.46 & 95.6 & 3.5 \\
\hline
\end{tabular}




\section{ACKNOWLEDGEMENTS}

This work was supported by the Foundation of National Natural Science foundation of China (Grant No. 41101223, 21372265), Natural Science Foundation of Yongchuan (Ycstc,2013nc8001), Foundation of Chongqing Education Commission of China (No. KJ131205) and Chongqing University of Arts and Science (No. Z2013CH05).

\section{REFERENCES}

1. S. Achmann, M. Hmmerle and R. Moos, Electroanalysis, 20, 410 (2008).

2. M.B. Ali, M. Gonchar, G. Gayda, S. Paryzhak, M.A. Maaref, N. Jaffrezic-Renault and Y. Korpan, Biosens. Bioelectron., 22, 2790 (2007).

3. A.A. Mohamed, A.T. Mubarak, Z.M.H. Marestani and K.F. Fawy, Talanta, 74, 578 (2008).

4. WHO, Formaldehyde, Environmental Health Criteria 89, Geneva (1989).

5. IARC, Monographs on the Evaluation of Carcinogenic Risks to Humans, Lyon, France, 88 (2006).

6. U.S. Environmental Protection Agency, Report to Congress on Indoor Air Quality, Washington, D.C. (1989).

7. WHO, Air Quality Guidelines for Europe, European Series, World Health Organization Regional Publications, edn 2, vol. 9 (2000); Available at http://www.who.dk.

8. K. Kawamura, K. Kerman, M. Fujihara, N. Nagatani, T. Hashiba and E. Tamiya, Sens. Actuators B, 105, 495 (2005).
9. N. Teshima, S.K.M. Fernández, M. Ueda, H. Nakai and T. Sakai, Talanta, 84, 1205 (2011).

10. R.A. Trenholm, F.L. Rosario-Ortiz and S.A. Snyder, J. Chromatogr. A, 1210, 25 (2008).

11. X. Xu, R. Su, X. Zhao, Z. Liu, D. Li, X. Li, H. Zhang and Z. Wang, Talanta, 85, 2632 (2011).

12. B. Deng, Y. Liu, H. Yin, X. Ning, H. Lu, L. Ye and Q. Xu, Talanta, 91, 128 (2012).

13. Y.-S. Wang, X. Tan, J.-H. Xue, G.-R. Li, L.-F. Shi, H.-M. Yang, L. Liu, B. Zhou and X.-L. Xiao, Anal. Chim. Acta, 690, 234 (2011).

14. H. Xie, C. Sheng, X. Chen, X. Wang, Z. Li and J. Zhou, Sens. Actuators $B, \mathbf{1 6 8}, 34$ (2012).

15. L. del Torno-de Román, M.A. Alonso-Lomillo, O. Domínguez-Renedo, C. Merino-Sánchez, M.P. Merino-Amayuelas and M.J. Arcos-Martínez, Talanta, 86, 324 (2011).

16. Y. Zhang, M. Zhang, Z. Cai, M. Chen and F. Cheng, Electrochim. Acta, 68, 172 (2012).

17. Q. Yi, F. Niu and W. Yu, Thin Solid Films, 519, 3155 (2011)

18. L. Zhuo, Y. Huang, M.S. Cheng, H.K. Lee and C.S. Toh, Anal. Chem., 82, 4329 (2010).

19. Y. Zhang, M. Zhang, Z. Cai, M. Chen and F. Cheng, Electrochim. Acta, 68, 172 (2012).

20. Z.L. Zhou, T.F. Kang, Y. Zhang and S.Y. Cheng, Microchim. Acta, 164, 133 (2009).

21. Q. Wang, J. Zheng and H. Zhang, J. Electroanal. Chem., 674, 1 (2012).

22. J. Wang, M. Pedrero and X. Cai, Analyst, 120, 1969 (1995). 